\title{
Human Adipose-derived Mesenchymal Stem Cells Attenuate Early Stage of Bleomycin Induced Pulmonary Fibrosis: Comparison with Pirfenidone
}

\author{
Manoj Reddy*, Lyle Fonseca*, Shashank Gowda, Basavraj Chougule, Aarya Hari, Satish Totey \\ Kasiak Research Pvt Ltd, DIL Complex, Thane, India
}

\begin{abstract}
Background and Objectives: Idiopathic pulmonary fibrosis (IPF) is a progressive, irreversible, invariably fatal fibrotic lung disease with no lasting option for therapy. Mesenchymal stem cells (MSCs) could be a promising modality for the treatment of IPF. Aim of the study was to investigate improvement in survivability and anti-fibrotic efficacy of human adipose-derived mesenchymal stem cells (AD-MSCs) in comparison with pirfenidone in the bleomycin-induced pulmonary fibrosis model.

Methods: Human AD-MSCs were administered intravenously on day 3, 6 and 9 after an intra-tracheal challenge with bleomycin, whereas, pirfenidone was given orally in drinking water at the rate of $100 \mathrm{mg} / \mathrm{kg}$ body weight three times a day daily from day 3 onward. AD-MSCs were labelled with PKH-67 before administration to detect engraftment. Disease severity and improvement was assessed and compared between sham control and vehicle control groups using Kaplan-Meier survival analysis, biochemical and molecular analysis, histopathology and high resolution computed tomography (HRCT) parameters at the end of study.

Results: Results demonstrated that AD-MSCs significantly increase survivability; reduce organ weight and collagen deposition better than pirfenidone group. Histological analyses and HRCT of the lung revealed that AD-MSCs afforded protection against bleomycin induced fibrosis and protect architecture of the lung. Gene expression analysis revealed that AD-MSCs potently suppressed pro-fibrotic genes induced by bleomycin. More importantly, AD-MSCs were found to inhibit pro-inflammatory related transcripts.

Conclusions: Our results provided direct evidence that AD-MSC-mediated immunomodulation and anti-fibrotic effect in the lungs resulted in marked protection in pulmonary fibrosis, but at an early stage of disease.
\end{abstract}

Keywords: Idiopathic pulmonary fibrosis, Mesenchymal stem cells, Adipose tissue, Pirfenidone, Bleomycin, HRCT

Accepted for publication August 12, 2016, Published online November 30, 2016

Correspondence to Satish Totey

Kasiak Research Pvt Ltd, DIL Complex, Ghodbunder Road, Thane (W)-400610, Maharashtra, India

Tel: +91-9833767533, Fax: +91-22-21739535

E-mail: smtotey@gmail.com

*These authors contributed equally to this work.

(a) This is an open-access article distributed under the terms of the Creative Commons Attribution Non-Commercial License (http://creativecommons.org/ licenses/by-nc/4.0/), which permits unrestricted non-commercial use, distribution, and reproduction in any medium, provided the original work is properly cited.

\section{Introduction}

Idiopathic pulmonary fibrosis (IPF) is a fatal fibrotic lung disorder of unknown aetiology and most common form of interstitial lung disease (ILD) with a prognosis worse than that of numerous cancers (1). Due to lack of understanding of IPF pathogenesis, effective treatment options are not available and hence IPF become a most life threatening disease with median survival time is around 2.5 to 3.5 years after diagnosis. Recently held theory about pathophysiology of IPF suggested association with multiple alveolar injuries, aberrant wound healing process, fail- 
ure of alveolar reepithelization, abnormal immune response and subsequent fibrosis (2). Multiple alveolar injuries are characterized by abnormal activation of alveolar epithelial cells (AEC), which secrets numerous mediators, like matrix metalloproteinase (MMP) that not only modify lung environment but also able to release, cleave and activate a wide range of growth factors, cytokines, chemokines such as transforming growth factor- $\beta$ (TGF- $\beta$ ), interleukin (IL)-1 $\beta$, IL-13 and C-C motif chemokine ligand-2 (CCL2) $(3,4)$. Continuous TGF- $\beta 1$ secretion by AEC in abnormal wound healing has a critical role in affecting numerous cell functions including adhesion, proliferation and promoting fibroblast differentiation into myofibroblasts through the process of epithelial mesenchymal transition (EMT) (5). However, recent studies have not shown EMT role in the context of pulmonary fibrosis (6). The myofibroblasts express smooth muscle actin and deposit excessive extracellular matrix (ECM) components at the site of injury resulting in the formation of fibrotic scar tissue (7).

Recently, FDA approved two novel drugs for IPF; pirfenidone and nintedanib. Pirfenidone is an anti-fibrotic, anti-inflammatory and anti-oxidant molecule which inhibits TGF- $\beta$ induced collagen synthesis, whereas, nintedanib is a tyrosine kinase inhibitor targeting vascular endothelial growth factor receptor (VEGFR), fibroblast growth factor receptor (FGFR) and platelet derived growth factor receptor (PDGFR) $(8,9)$. Pirfenidone showed decline in forced vital capacity (FVC), incidence of acute IPF exacerbation and increase in progression free survival in some clinical trials (10). Pirfenidone reduces growth factor-driven fibroblast proliferation and ECM production in vitro and attenuate experimentally induced pulmonary fibrosis in animal model (11). Although, pirfenidone effects reported in few clinical trials were inconclusive, but independent meta-analysis of all IPF clinical trials reported some treatment benefits (12).

Due to lack of effective and limited therapies, there is an urgent need of innovative approaches and new therapies that could provide complete remission from the disease. Stem cell therapy could be one such approach due to their immunomodulatory, anti-inflammatory and anti-fibrotic properties (13). In recent years, there has been a keen interest in stem cell research primarily due to their true potential and promise that they offer to the patients as a cell therapy with the hope to treat many incurable diseases (14). MSCs have currently been a subject of interest since they secretes several growth factors, cytokines, chemokines and basic proteins, decrease ECM, collagen deposition and contribute to tissue repair (15). They can alter the lung microenvironment by secreting anti-inflammatory cytokines that lead to an attenuation of fibrosis and restoration of the alveolar architecture (16-19). After many years of investigation, the use of stem cells to treat IPF is still at an experimental stage and recently concluded few clinical trials have not either shown any significant clinical outcome $(17,19)$. In one of the systemic pre-clinical review it was assessed that stem cells offer better support for efficacy in the initial inflammatory phase rather than the fibrotic phase (20).

In view of this, in the current study, we have investigated the efficacy of human AD-MSCs in a murine model of bleomycin induced lung fibrosis and compared with current available standard medication pirfenidone. Aim of this comparison was to use of pirfenidone as standard drug control arm in human clinical trials with the stem cell in order to avoid excess acute exacerbation in control arm. Here, we have demonstrated the anti-inflammatory and anti-fibrotic actions of systemically administered $\mathrm{AD}-\mathrm{MSC}$ in ameliorating the symptoms of bleomycin-induced lung fibrosis and improvement in survivability.

\section{Materials and Methods}

\section{Isolation and Culture of human AD-MSCs}

Approximately, $100 \mathrm{ml}$ of human lipoaspirate $(\mathrm{n}=10)$ were obtained by vaser assisted liposuction from abdominal subcutaneous fat from voluntary healthy human donors. All the donors were pre-screened for infectious diseases and comprehensive health conditions before included in the study. Written informed consent was obtained before lipoaspiration and project was duly approved by Institutional Committee for Stem Cell Research and Therapy (ICSCRT) and Institutional Ethics Committee (IEC). Sample processing was done inside a class 100 biosafety hood in a class B cGMP: current good manufacturing practices, facility. Adipose tissues were washed thoroughly with Dulbecco's phosphate buffered saline (DPBS) (Invitrogen, Bangalore, India) and subjected to digestion with freshly prepared $2 \mathrm{mg} / \mathrm{ml}$ collagenase Type-I (MP Biomedical, Santa Ana, CA) for 60 minutes at $37^{\circ} \mathrm{C}$ under gentle agitation. To the digested adipose tissue, an equal volume of growth medium, consisting of Dulbecco's modified Eagle's medium-knockout (DMEM-KO) (Invitrogen) supplemented with $10 \%$ fetal bovine serum (FBS), (Hyclone, South Logan UT), $2 \eta \mathrm{g} / \mathrm{ml}$ basic fibroblast growth factor (bFGF) and 1\% GlutaMAX (Invitrogen) was added to neutralize the enzyme. The suspension was then centrifuged at $2500 \mathrm{rpm}$ for 10 minutes. The resulting cell pellet was then re-suspended in growth medium. The re- 
sulting cell suspension obtained was the stromal vascular fraction (SVF). The SVF was first filtered through a 100$\mu \mathrm{m}$ filter and then through a $40-\mu \mathrm{m}$ filter (Millipore India, Bangalore, India).

\section{Preparation of master cell bank (MCB), working cell bank (WCB) and investigational product (IP)}

Clinical grade MCB, WCB and IP was prepared as per the method described earlier (21). Briefly, SVF from each donor was seeded separately on to 2-chamber cell stack (corning plastic wares supplied by Sigma Aldrich, Bangalore, India) in growth medium at a density of $85,000 \sim 100,000$ cells $/ \mathrm{cm}^{2}$ and incubated at $37^{\circ} \mathrm{C}$ in $5 \%$ humidified $\mathrm{CO}_{2}$. The medium was changed every third day, and cells were harvested once they became confluent $\sim 70 \%$ with $0.05 \%$ trypsin plus $0.2 \%$ Ethylenediaminetetraacetic acid (EDTA), washed with DPBS and counted with haemocytometer. The cells from the individual donors were tested for quality parameters. The cells were aliquoted and frozen at the concentration of 1 million cells $/ \mathrm{ml}$ and stored in vapour phased liquid nitrogen at passage- 0 .

For WCB, frozen vials of MCB from five different donors were thawed and cells were pooled together. Mixed donor cells were then seeded onto 5-chamber cells stack (Corning) in growth medium at the seeding density of 3000 cells $/ \mathrm{cm}^{2}$ and cultured as described above. Cells were harvested once they reached $\sim 70 \%$ confluence. Cells of the WCB were tested for quality parameters and were frozen at the concentration of 3 million cells/vial and stored in vapour phase liquid nitrogen at passage-1.

The IP was prepared by seeding frozen-thawed WCB at a seeding density of 3000 cells $/ \mathrm{cm}^{2}$ in a 10 -chamber cells stack (Corning) containing growth medium and cultured as described above. The cells were harvested once they reached $\sim 70 \%$ confluent. IP was then tested for quality parameters and used for pre-clinical study. Remaining batch was frozen at the concentration of 100 million cells/cryocyte bag and stored in vapour phased liquid nitrogen at passage- 2 .

\section{Quality control testing}

The MCB, WCB and IP were tested for quality parameters as per the guidelines of Central Drug Standard Control Organization (CDSCO), India. Details are given in Table 1. Briefly, quality control was carried out broadly under following categories. Purity was tested by analysing cell morphology and immunophenotypic analysis for hematopoietic and mesenchymal stem cell markers using flow cytometry for CD34, CD45, CD73, CD90, CD105, CD166 and HLA-DR as per the method described earlier (15).
Potency of the cells was carried out by testing cell viability by flow cytometry using 7-aminoactinomycin D (7AAD), tri-lineage differentiation potential for osteoblasts, adipocytes, chondrocytes as per the method described earlier (22), secretome analysis using multiplex Elisa (Invitrogen), immunomodulation by testing suppression of T-cell proliferation by AD-MSC and pluripotent markers like OCT4, Nanog, SOX-2, REX-1 and ABCG2 by real time PCR $(15,23)$. Safety of the cells was tested by bacterial endotoxin using Lal Test (Charles River, Wilmington, MA (specification $<0.5 \mathrm{EU} / \mathrm{ml}$ ), mycoplasma testing using PCR (Venor Gem, Minerva Biolab, Berlin, Germany), sterility by BactAlert 3D automated system (Biomeurix, France) for 7 days, karyotyping by $G$ banding, viral screening for human immunodeficiency virus (HIV) 1,2, hepatitis $\mathrm{B}$ virus (HBV), hepatitis $\mathrm{C}$ virus (HCV), cytomegalovirus (CMV), and venereal disease research laboratory (VDRL) tests by polymerase chain reaction (PCR) and transformation markers like MYC, ERCC3, XRCC4 and RAD51 (15). Toxicity studies was carried out at third party accredited good laboratory practice (GLP) animal facility for acute toxicity in mice and rat using two infusion routes like intravenous (IV) and intramuscular (IM) and

Table 1. Typical quality parameters carried out for clinical grade MCB, WCB and IP as per the regulatory guidelines

\begin{tabular}{|c|c|}
\hline Purity & $\begin{array}{l}\text { - Morphology } \\
\text { - Immunophenotyping }\end{array}$ \\
\hline Potency & $\begin{array}{l}\text { - Differentiation } \\
\text { - Viability } \\
\text { - Secretome analysis by multiplex Elisa } \\
\text { - Immunomodulation (Suppression of } \\
\text { T cell proliferation) }\end{array}$ \\
\hline Safety & $\begin{array}{l}\text { - Sterility } \\
\text { - Endotoxin } \\
\text { - Mycoplasma } \\
\text { - Karyotyping } \\
\text { - Viral screening (HIV1,2, HBV, HCV, } \\
\text { VDRL, CMV) } \\
\text { - Transformation markers (MYC, ERCC3, } \\
\text { XRCC4, RAD51) }\end{array}$ \\
\hline Pharmacodynamics & - Bio-distribution \\
\hline Pharmacokinetics & - Efficacy model study \\
\hline $\begin{array}{l}\text { GLP Toxicity } \\
\text { studies }\end{array}$ & $\begin{array}{l}\text { - Acute toxicity in rat and mice } \\
\text { by IV and IM } \\
\text { - } 21 \text { days repeated dose toxicity study } \\
\text { in rat IV }\end{array}$ \\
\hline Stability of IP, & - MCB stability for 5 years (Every 6 month) \\
\hline WCB and IP & $\begin{array}{l}\text { - WCB stability for } 2 \text { years (Every } 4 \text { month) } \\
\text { - IP stability for } 6 \text { months (Every } 2 \text { month) }\end{array}$ \\
\hline $\begin{array}{l}\text { Finished products } \\
\text { trace element }\end{array}$ & $\begin{array}{l}\text { - Fetal bovine serum traces } \\
\text { - Trypsin traces }\end{array}$ \\
\hline
\end{tabular}


four doses like 5, 10, 15 and $20 \times 10^{6}$ cells/kg body weight. Twenty one days repeated dose toxicity study in rat using IV route was also carried out. Pharmacodynamics was carried out using bio-distribution study and pharmacokinetics study was carried out as efficacy model study as stated in this paper and finally stability testing was carried out for MCB, WCB and IP and determined by viability, MSC cell surface markers analysis, tri-lineage differentiation capacity and colony forming unit (CFU) assays. Final product was tested for trace elements of trypsin and fetal bovine serum (Table 1). Batches were released for pre-clinical and clinical applications once they satisfied quality parameters set by the CDSCO and drug controller general of India (DCGI) (21).

\section{Animals and experimental design}

Animals: Male Swiss-albino mice (10 12 weeks of age, weighing 18 22 g) were obtained from Jackson Laboratories (Bar Harbour, ME, USA) and housed in individually ventilated cages in a temperature-controlled room, with access to food and water ad libitum. All animal experiments were carried out in an animal house of Bharat serums and vaccine Ltd, Mumbai, India and were double blinded and handled in accordance with the guidelines of "Committee for the Purpose of Control and Supervision of Experiments on Animals" (CPCSEA). All animal experiments were approved by Institutional Animal Ethics Committee (IAEC) and CPCSEA. Total 50 animals per experiment were divided into five groups $(n=10)$ as follows: naïve control, sham control, vehicle control, ADMSC treated and pirfenidone treated. Each experiment was replicated three times (Total 150 animals) (Table 2).

Mice were anesthetized with 5\% isoflurane and administered single bleomycin sulphate (MP Biomedical, Mumbai, India) at the dose of $0.004 \mathrm{U} / \mathrm{gm}$ of mice dissolved in $0.9 \%$ sterile normal saline in $50 \mu 1$ volume via intra-tracheal route on day 0 . Sham control animals received equal volume of sterile phosphate buffered saline (PBS) via intra-tracheal route. To probe the efficacy of
AD-MSCs, a treated group of mice were given intravenous administration of frozen-thawed IP suspended in Plasmalyte-A (Baxter, India) at the concentration of $40 \times 10^{6}$ cells/kg body weight, (equivalent to human dose of $2 \times 10^{6} / \mathrm{kg}$ body weight) via tail vein on day 3,6 and 9 of post bleomycin administration. In standard treatment group, pirfenidone was given orally in drinking water at the rate of $100 \mathrm{mg} / \mathrm{kg}$ body weight from day 3 to 23 post bleomycin, daily thrice in a day (T.I.D.). In vehicle control and sham control group $0.5 \mathrm{ml}$ Plasmalyte-A was injected on day 3, 6 and 9. All the experiments were terminated on day 24, mice were analysed for survivability, gross pathology, biochemical and molecular analysis, histopathology and HRCT as per the recommendations of American thoracic society workshop (24).

\section{High-resolution computed tomography (HRCT)}

All the animals were scanned for HRCT at Advanced Centre for Treatment, Research, Education in Cancer (ACTREC), Mumbai, India, as per the method described earlier (25). Briefly, experimental animals were scanned on day 21 post-administration of bleomycin. Mice were anesthetized intraperitoneally with ketamine hydrochloride (Sun Pharma, Mumbai, India; $100 \mathrm{mg} / \mathrm{kg}$ ) and xylazine (Indian Immunological, Hyderabad, India; $10 \mathrm{mg} / \mathrm{kg}$ ) in order to maintain hypnosis during HRCT. Scanning was performed with a FLEX-Triumph ${ }^{\mathrm{TM}}$ CT-scanner imaging platform (Gamma Medica). Acquisition parameters were $50 \mathrm{kw}, 512$ projections at $360^{\circ} \mathrm{C}$ (1 projection $=$ $280 \mathrm{~ms}$ ), average field of view $5 \mathrm{~cm}$, thin-section slices, each of $0.625 \mathrm{~mm}$ in thickness, and spaced $1 \mathrm{~mm}$ apart covered the complete mouse lung from the apex to the hemi-diaphragm. Images were acquired in axial plane and the bone algorithm was applied to better visualize the lung. Around 20 to 22 slices covered the entire animal lungs. Following the scan, the mice were placed in their cages, recovering from the anaesthesia. Post-scan care was taken and animals were supplied with standard laboratory diet and water ad libitum.

Table 2. Experimental design

\begin{tabular}{|c|c|c|c|c|}
\hline Groups & $\begin{array}{l}\text { No of Animals } \times \\
\text { Replicates }\end{array}$ & Sex & $\begin{array}{l}\text { Induction } \\
\text { of IPF }\end{array}$ & Treatment \& Duration \\
\hline Naïve control & $10 \times 3$ & M & - & Plasmalyte-A (iv); Day 3, 6, 9 post BLM \\
\hline Sham control & $10 \times 3$ & M & PBS & Plasmalyte-A (iv); Day 3, 6, 9 post BLM \\
\hline Vehicle control & $10 \times 3$ & M & BLM & Plasmalyte-A (iv); Day 3, 6, 9 post BLM \\
\hline AD-MSC & $10 \times 3$ & M & BLM & $40 \times 10^{6} / \mathrm{kg}$ BW (iv) day $3,6,9$ post BLM \\
\hline Pirfenidone & $10 \times 3$ & M & BLM & Daily $100 \mathrm{mg} / \mathrm{kg}$ BW; T.I.D, Day 3-23 \\
\hline
\end{tabular}

BLM: Bleomycin, PBS: Phosphate buffered saline, TID: Thrice in a day, iv: intravenous, M: males. 


\section{Hydroxyproline estimation}

The hydroxyproline content was assessed to indicate the extent of collagen deposition in the lungs. To estimate the hydroxyproline content, lung tissue homogenates were hydrolysed in $6 \mathrm{~N}$ hydrochloric acid (Sigma Aldrich) for 16 $\mathrm{h}$ at $120^{\circ} \mathrm{C}$. An aliquot of these hydrolysates was then assayed using a hydroxyproline estimation kit (BioVision Research Products, Milpitas, CA, USA). Briefly, hydrolysates were incubated with Chloramine- $T$, followed by colour development with Ehrlich's reagent at $65^{\circ} \mathrm{C}$ for 90 min. The absorbance at $550 \mathrm{~nm}$ was measured by iMark Microplate Reader (Bio-Rad, Hercules, CA, USA). Hydroxyproline levels were determined by plotting standard curve using serial dilutions of hydroxyproline standard. Results were quantified as $\mu \mathrm{g} / \mathrm{lung}$.

\section{Histological evaluations}

Lung biopsies were fixed in 10\% neutral buffered formalin. Paraffin embedded sections (5 $\mu \mathrm{m}$ thickness) of the lung specimens were stained with haematoxylin (Sigma Aldrich) and eosin (Loba Chemie, Mumbai, MH, India) and Masson's trichrome (Sigma Aldrich) stain for collagen deposition. Sections were graded by an investigator blinded to the treatment groups. Modified Ashcroft's scoring was performed on a scale of 0 to 8 to determine the extent of fibrosis as described elsewhere (26).

\section{AD-MSCs homing and localization studies}

To qualitatively assess the homing potential of systemically administered AD-MSCs, cells were stained with PKH-67 fluorescent cytosolic dye (Sigma Aldrich) prior to injection into mice. Post sacrifice, fluorescence imaging of cryotome sections of the lung tissues was carried out using the Nikon Eclipse Ti inverted fluorescence microscope (Nikon Instruments Inc., Melville, NY, USA). PKH-67 tagged cells were visualized using the green fluorescent filter (excitation - $490 \mathrm{~nm}$, emission - $502 \mathrm{~nm}$ ). To observe their distribution in the lung tissues, the sections were then stained with 10 EM Hoechst 33342 (AnaSpec Inc.; Fremont, CA, USA) and visualized under the blue fluorescent filter (excitation - $358 \mathrm{~nm}$, emission - $461 \mathrm{~nm}$ ). The images were then superimposed using the NIS elements imaging software to create a composite image.

\section{Pro-inflammatory and pro-fibrotic marker analysis in lung}

Total cellular RNA was extracted from lung tissues of mice and purified using the PureLink RNA Mini Kit (Invitrogen). RTQ-PCR analysis was carried out using the express SYBR GreenER qPCR Supermix kit (Invitrogen).
The primers used were designed using primer 3 software and custom synthesized (Bioserve, Hyderabad, India). Melting curve analysis was performed at the end of PCR and changes in gene expression were analysed using the 'StepOne Plus' software (version 1.1). The relative expression of each gene was calculated using the comparative Ct method. Relative quantification of target mRNA expression was calculated and normalized to GAPDH expression. The results are presented as the $\log 2$ fold change of mRNA expression as compared to the amount present in vehicle control samples.

\section{Statistical analysis}

Data was pooled from both the experiments and expressed as mean \pm SEM unless otherwise stated. Comparisons between two groups were determined using a twotailed Student's t-test. For multiple comparisons, one-factor analysis of variance was used, followed by the appropriate ad-hoc test as dictated by the normality and distribution of the data. The survival curves were calculated by the Kaplan-Meier method, and differences between survival curves were compared by the log-rank test. All statistical analysis was performed using SPSS software (version 13 for Windows; SPSS, Inc., Chicago, IL, USA). $\mathrm{p}$ values less than or equal to 0.05 were considered significant and expressed as $\mathrm{p}<0.01 ; \mathrm{p}<0.001$.

\section{Results}

\section{Cell characterization and quality parameters}

Purity of the MSCs derived from adipose tissue as MCB, WCB and IP maintained normal phenotypes which were typically small, spindle-shaped appearance in all the passages (Fig. 1A). Immunophenotypic analysis by flow cytometry showed less than $0.2 \%$ hematopoietic cell surface markers like CD34 and CD 45 (Fig. 1E, F) and more than $99 \%$ MSC stem cell population characterized by CD73, CD90, CD105, CD166 (Fig. 1H-K) that represent homogeneous cell population. Expression of HLA-DR was also found to be less than $0.2 \%$ (Fig. 1G).

Potency of the MSC was tested by cell viability, tri-lineage differentiation, secretome analysis and immunomodulation assays. Cell viability by 7-AAD staining for exclusion of non-viable cells, followed by flow cytometric analysis was found to be $>97 \%$ viable population (Fig. 1D). Potential of tri-lineage differentiation into adipocyte showed uniform Oil Red O staining for neutral lipid vacuoles (Fig. 2A). Similarly, Von-Kossa assay showed mineralized deposits in osteo-induced culture of AD-MSC (Fig. 2B) and also retained the ability to differentiate into 
A

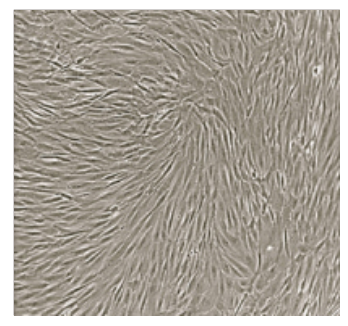

E

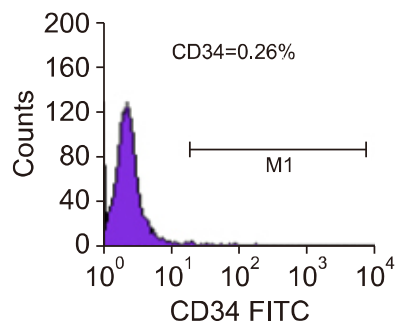

I

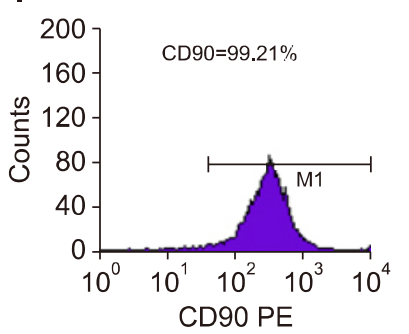

B

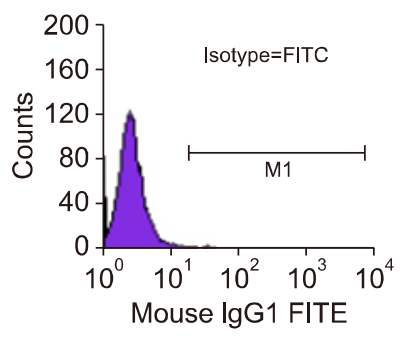

$\mathbf{F}$

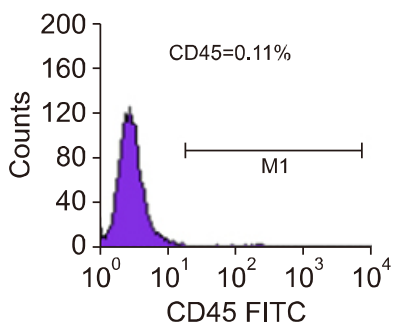

J

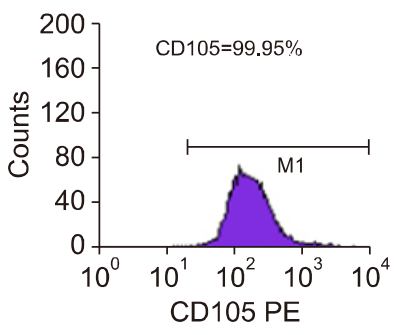

C

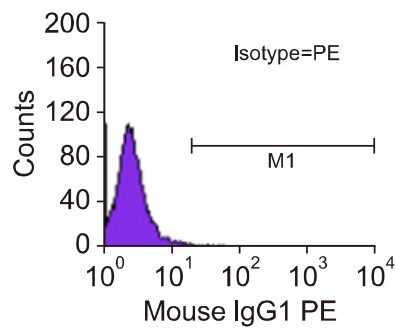

G

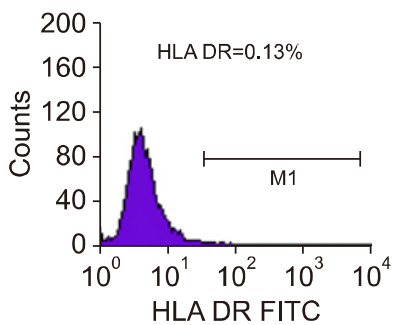

$\mathrm{K}$

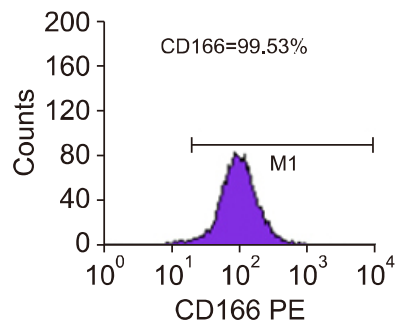

D

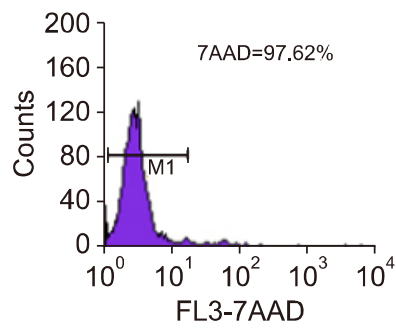

H

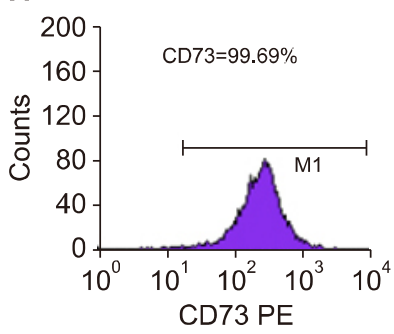

Fig. 1. Morphology and Immunophenotyping of AD-MSCs. (A) AD-MSCs demonstrated long, spindle shaped fibroblast like appearance. (B) Isotype-Fluorescein isothiocynate (FITC). (C) Isotype-Phycoerythrin (PE). (D) Histogram representing flow cytometric analysis of 7-AAD labelled cells revealed $>98 \%$ viability of AD-MSCs. (E $\sim \mathrm{G})$ Histograms representing flow cytometric analysis of hematopoietic cell markers revealed $<0.2 \%$ of $\mathrm{CD} 34, \mathrm{CD} 45$ and HLA-DR. $(\mathrm{H} \sim \mathrm{K})$ Histograms representing flow cytometric analysis of AD-MSC positive markers revealed $>99 \%$ of CD73, CD90, CD105 and CD166 positive cells, $189 \times 239 \mathrm{~mm}(150 \times 150 \mathrm{DPI})$.

chondrocytes as shown by Alcian blue staining (Fig. 2C). We did not find any visible detectable differences in the potential of tri-lineage differentiation in MCB, WCB and IP. Potency of AD-MSCs was also tested by secretome analysis by multiplex Elisa and showed high amount of secretary growth factors, cytokines and chemokines. Level of secretome was at increasing trend with highest at IP level (Fig. 2E).

Safety of the cells was tested and found negative for mycoplasma, bacterial endotoxin was less than $0.06 \mathrm{EU} / \mathrm{ml}$, and infectious diseases like HIV 1,2, HCV, HBV, CMV and VDRL testing was found negative. Safety was also proven by acute toxicity and 21 days repeated dose toxicity studies. All the AD-MSC batches were passed through sterility test, had normal karyotyping (Fig. 2D) and high expression of pluripotent markers.

Stability data for MCB, WCB and IP was also shown very robust MSC batch with no significant detectable differences in viability, tri-lineage differentiation capacity, cell surface marker analysis and colony forming unit potential even after 3 years of MCB batch study. Detail quality analysis and its specification and results obtained are given in Table 1 and 3.

\section{Survivability analysis}

Dose of $0.004 \mathrm{U} / \mathrm{g}$ of bleomycin induced severe pulmonary fibrosis in Swiss-albino mice. Survival analysis was carried out by Kaplan-Meier survival analysis and compared with vehicle control group. Results showed that, over the first 15 days, half of the vehicle control animals failed to survive the single bleomycin infusion. On the contrary, survivability was significantly prolonged in the mice treated with AD-MSCs and $66.66+3.3$ percent animals were survived at the end of the study compared to vehicle control group $(p<0.001)$. Survivability was also significantly improved in pirfenidone treated mice compared to vehicle control group and showed $53.33+3.3$ percent survivability at the end of the study $(p<0.01)$ However, 
A

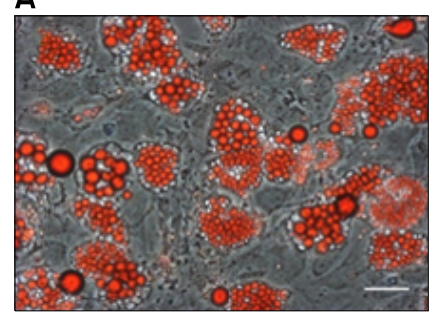

B

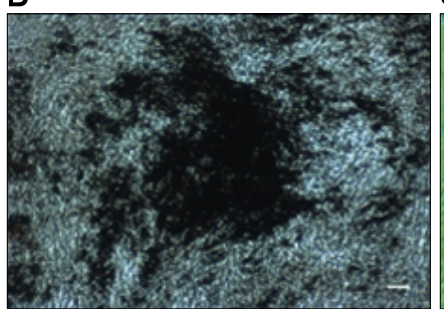

C

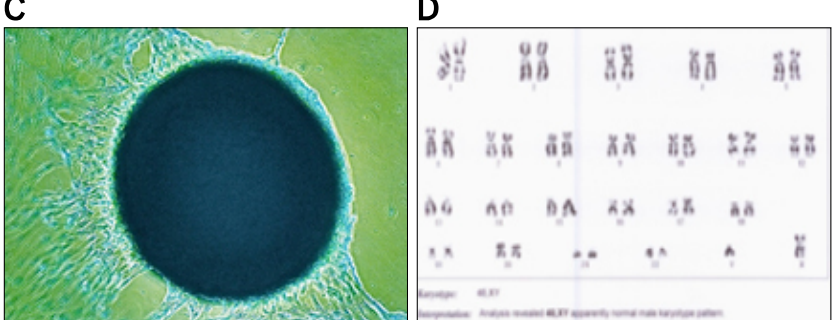

$\mathrm{E}$
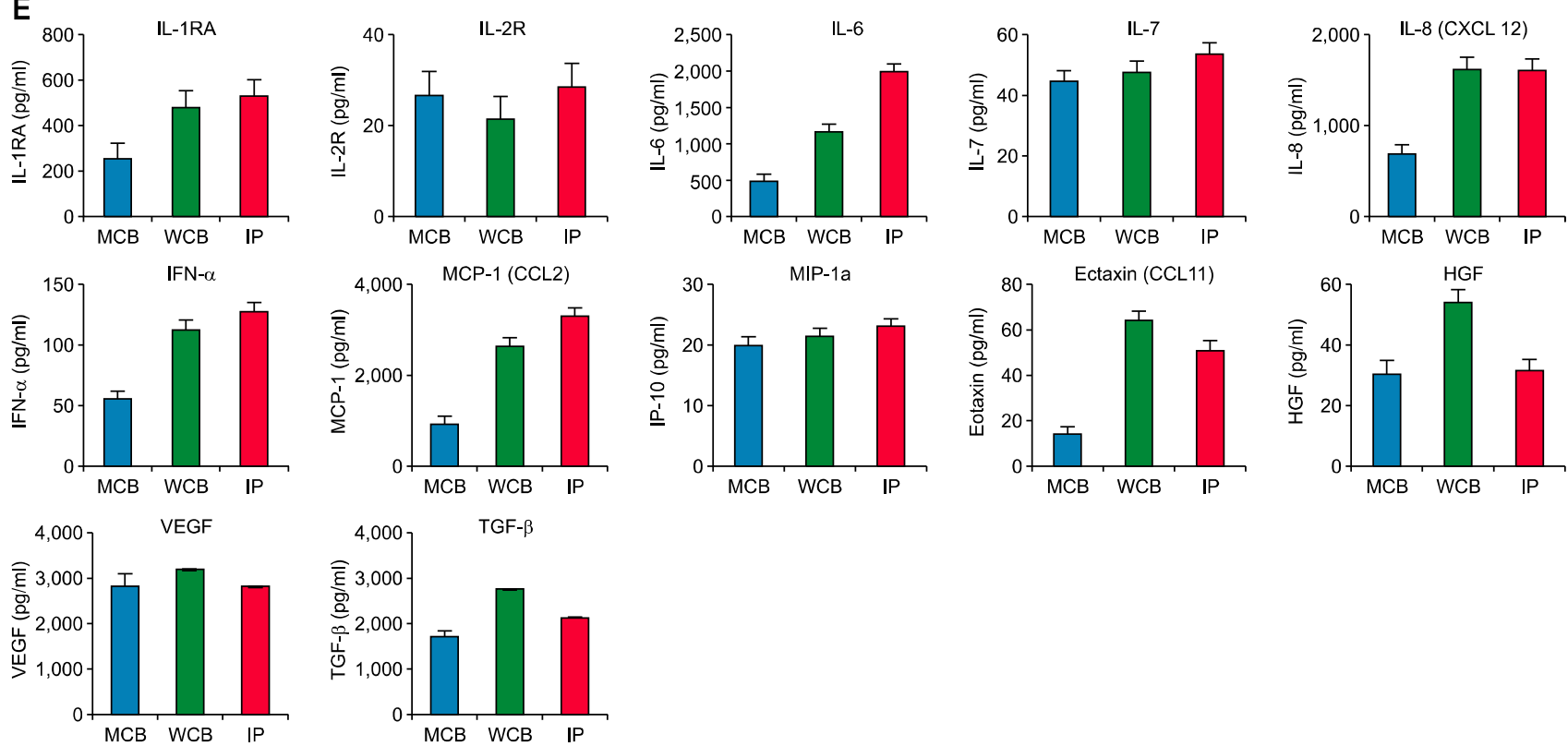

Fig. 2. Representative data of quality control testing for $M C B, W C B$ and IP. (A) Adipogenesis was detected by neutral oil droplet formation stained with Oil Red $\mathrm{O}$ at day 21. (B) Osteogenesis was confirmed by mineralized matrix deposition stained with Von-Kossa at day 21. (C) Chondrogenesis was detected by the presence of proteoglycans stained with Alcian Blue staining at day 21. (D) Cytogenetic stability of AD-MSC under prolonged culture. (E) Multiplex Elisa assays for secretome analysis of MCB, WCB and IP showed very high secretion of growth factors, cytokines and chemokines in the conditioned media. Results are representative of three experiments.

survivability was significantly better in AD-MSCs treated mice than pirfenidone $(\mathrm{p}<0.05)$ (Fig. 3). Results therefore concluded that, AD-MSCs treatment significantly improve survivability better than pirfenidone in bleomycin induced IPF.

\section{AD-MSCs abrogate bleomycin-induced collagen deposition in lungs}

The observations that uncontrolled inflammatory responses in the lungs and aberrant repair mechanisms have been implicated in the pathogenesis of IPF, combined with the findings that therapies targeting inflammation and fibrosis have proved quite successful in reducing the severity of experimental pulmonary fibrosis, led us to hypothesize that human AD-MSCs (which exhibit immunomodulatory properties) could be efficacious in a murine model of pulmonary fibrosis.
Bleomycin-induction of pulmonary fibrosis was manifested with a significant increase in collagen deposition in lungs of mice due to excessive scar tissue formation (Fig. 4B) and led to a marked increase in the overall weight of the lungs (Fig. 4E). Consistent with these observations, bleomycin treatment significantly increases the collagen deposition in the lungs as evidenced by increased lung weights and a corresponding increase in levels of hydroxyproline (Fig. 4F). More importantly, intravenous administration of AD-MSCs showed significant inhibition of bleomycin-induced lung fibrosis (Fig. 4C) and significant reduction in collagen deposition as evidenced by significant reduction of lung weights $(p<0.001)$ and decrease in levels of hydroxyproline $(\mathrm{p}<0.001)$ (Fig. 4E, F). These results were significantly better than pirfenidone treated group. 
Table 3. Specification and results of quality control parameters tested on MCB, WCB and IP batch used for current experiment

\begin{tabular}{|c|c|c|c|c|}
\hline Tests & Specification & MCB & WCB & IP \\
\hline Morphology & $\begin{array}{l}\text { Slender, fibroblast like } \\
\text { appearance }\end{array}$ & Confirmed & Confirmed & Confirmed \\
\hline Bacterial Endotoxin & $<0.5 \mathrm{EU} / \mathrm{ml}$ & $<0.06 \mathrm{EU} / \mathrm{ml}$ & $<0.06 \mathrm{EU} / \mathrm{ml}$ & $0.06 \mathrm{EU} / \mathrm{ml}$ \\
\hline Mycoplasma PCR & ND & ND & ND & ND \\
\hline $\mathrm{pH}$ & 7.0 to 7.6 & 7.26 & 7.38 & 7.34 \\
\hline Sterility test & Must comply & Complies & Complies & Complies \\
\hline \multicolumn{5}{|l|}{ Purity } \\
\hline CD34 & $10 \%$ & $2.60 \%$ & $0.70 \%$ & $0.26 \%$ \\
\hline CD45 & $10 \%$ & $1.70 \%$ & $0.22 \%$ & $0.11 \%$ \\
\hline CD73 & $85 \%$ & $99.55 \%$ & $99.83 \%$ & $99.69 \%$ \\
\hline CD90 & $85 \%$ & $99.15 \%$ & $99.94 \%$ & $99.21 \%$ \\
\hline CD105 & $85 \%$ & $99.21 \%$ & $99.63 \%$ & $99.95 \%$ \\
\hline CD166 & $85 \%$ & $99.04 \%$ & $99.56 \%$ & $99.53 \%$ \\
\hline HLA-DR & $10 \%$ & $3.10 \%$ & $1.78 \%$ & $0.13 \%$ \\
\hline Viability (7AAD) & $85 \%$ & $94.65 \%$ & $98.67 \%$ & $99.32 \%$ \\
\hline Tri-lineage Differentiation & Confirmed & Confirmed & Confirmed & Confirmed \\
\hline Karyotyping & Normal & Normal & Normal & Normal \\
\hline $\begin{array}{l}\text { ID Screening HIV-1,2, HBV, } \\
\text { HCV, CMV, VDRL }\end{array}$ & Negative & Negative & Negative & Negative \\
\hline
\end{tabular}

ND: Not detected, ID: Infectious Diseases, HIV: Human immunodeficiency virus, HBV: Hepatitis B virus, HCV: Hepatitis C virus, CMV: Cytomegalovirus, VDRL: Venereal Disease Research Laboratory.

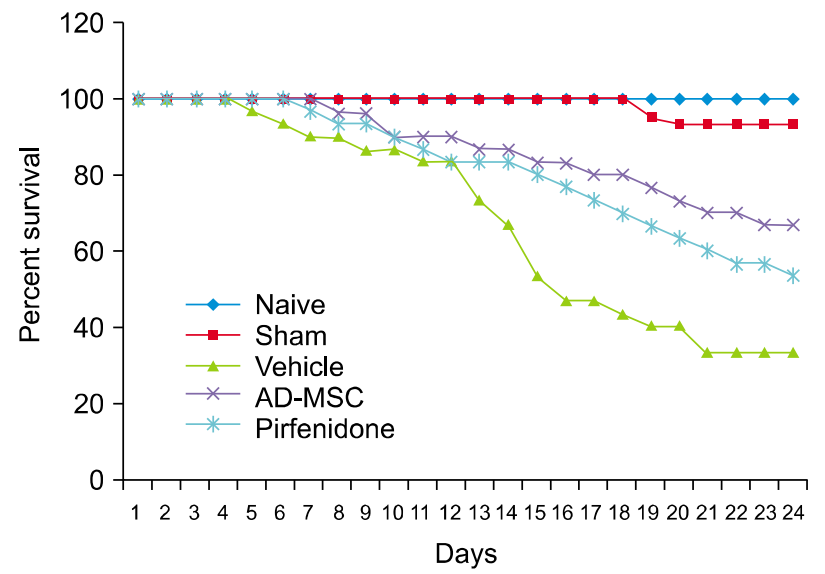

Fig. 3. Kaplan-Meier estimates of survival for animals with bleomycin induced pulmonary fibrosis.

\section{AD-MSCs attenuate fibrosis and maintain alveolar architecture of diseased lungs}

Histological analysis confirmed the bleomycin-induction of fibrosis. Lung tissue sections from IPF induced mice, but not from normal mice, revealed severe fibrosis, characterized by the presence of fibrotic masses, collapsed alveoli with severely thickened alveolar septa along with extensive tissue scarring (Fig. 5B). In contrast, tissue sections from AD-MSC (Fig. 5C), pirfenidone-treated bleomycin mice (Fig. 5D) revealed attenuation in fibrosis with mild thickening of alveolar septa, protection against bleomycin-induced lung fibrosis and maintenance of alveolar architecture. Modified Aschcroft's scores were performed in a blinded fashion, to quantify lung damage. This analysis revealed significant difference between bleomycin groups demonstrating that AD-MSC and pirfenidone treatment improved the lung architecture $(\mathrm{p}<0.01)$ (Fig. 5E).

\section{Homing and engraftment potential of systemically administered AD-MSCs at the site of injury}

Intra-tracheal administration of bleomycin in mice induces localized inflammation that can be evidenced by the disruption of normal alveolar architecture and lung parenchyma. This chemokine rich environment at the site of injury acts as a potent inducer of MSC migration that results in the homing of systemically administered ADMSCs into the lung after bleomycin induced tissue damage. Prior studies have also demonstrated that AD-MSCs maximally retain into the lung when administered intravenously through the tail vein. Therefore, in order to investigate the homing and engraftment potential of AD-MSCs, cells were tagged with PKH-67 cytosolic stain, immediately before intravenous administration to mice. Fluorescence photomicrographs of lung sections of AD-MSC treated animals revealed that PKH-67 labelled cells demonstrated homing and engraftment potential towards the damaged lung tissue and were detected even at day 24 after administration 

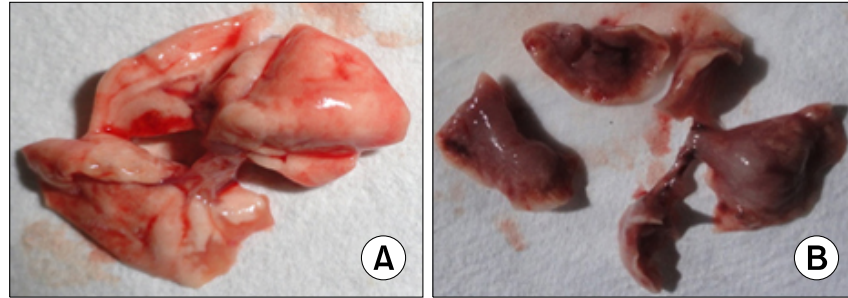

(B)

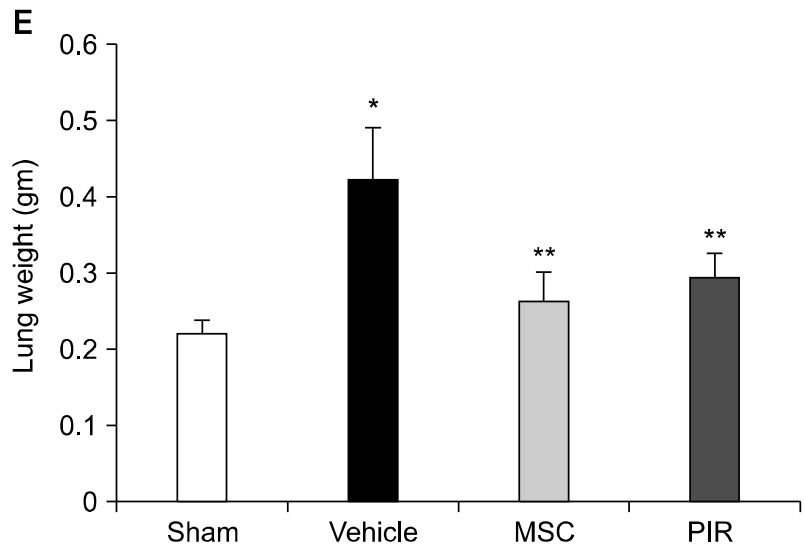

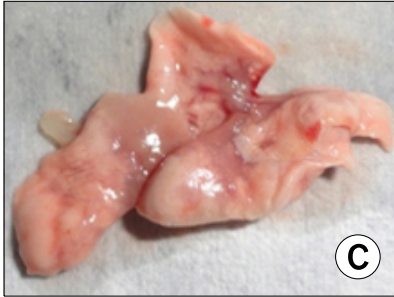

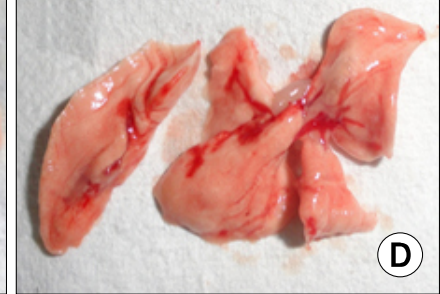

$\mathrm{F}$

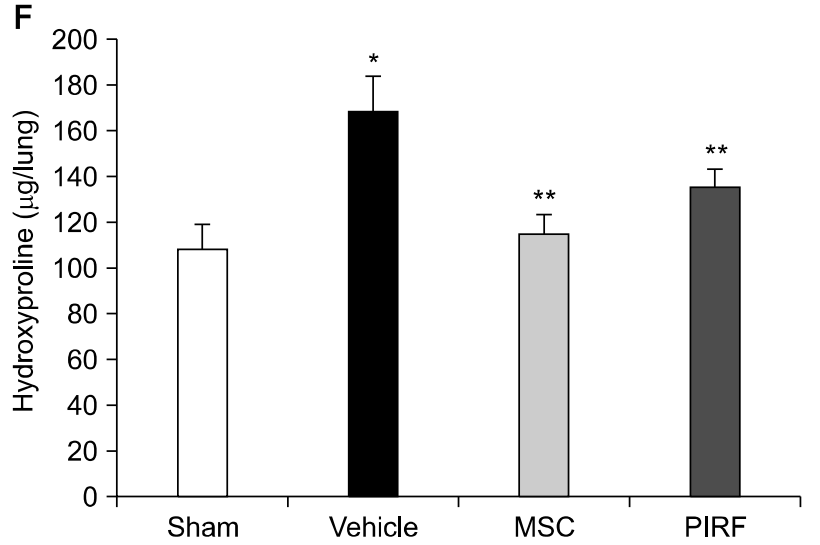

Fig. 4. Representative figure of Gross pathology of A. sham control lung, B. Vehicle control lung with severe fibrosis, C. AD-MSC treated lung with partial reversal of fibrosis with small fibrotic patches, D. pirfenidone treated lung with partial reversal of fibrosis and few fibrotic areas. AD-MSCs abrogate bleomycin-induced collagen deposition in lungs. (E) A reduction in lung weight is observed in the AD-MSC treated group when compared to the vehicle control group. All values are averages \pm S.E.M. (F) Levels of collagen deposition in the lung are determined by hydroxyproline estimation. Vehicle control mice show increased levels of hydroxyproline due to bleomycin-induced lung damage. On treatment with AD-MSCs a reduction in levels of hydroxyproline was observed. All values are averages \pm S.E.M. Results presented are representative of 3 separate experiments. $90 \times 120 \mathrm{~mm}(150 \times 150 \mathrm{DPI})$.

(Fig. 6).

\section{AD-MSCs exert their mechanism by down-regulating pro-inflammatory and pro-fibrotic transcripts in damaged lungs}

To demonstrate the reduction in inflammation and fibrosis of bleomycin-induced lung injury by AD-MSCs, we studied mechanisms that mediate this effect. We observed that AD-MSCs down-regulated the expression of pro-inflammatory cytokines IL2, IL1b, tumour necrosis factor (TNF) and TGF $\beta$ which led to a reduction in inflammation (Fig. 7A) and the expression of pro-fibrotic mediators, bFGF, connective tissue growth factor (CTGF), collagen (COL)3al and CoLlal which led to reduction of pulmonary fibrosis (Fig. 7B). Furthermore, we observed that AD-MSCs downregulated the elevated expression of matrix metalloproteinases (MMPs) (Fig. 7B) which in turn downregulated the expression of tissue inhibitor of metalloproteinases (TIMPs) (Fig. 7B), thus maintaining the MMP-TIMP balance and preventing the restructuring of the matrix caused due to bleomycin-induced lung injury. This reduction in cellular restructuring led to a reduction of collagen deposition and subsequent attenuation of fibrosis.

\section{HRCT analysis}

The HRCT features of IPF are more representative of the pathologic process. Selected parameters, such as distribution of fibrotic and honeycombing, consolidation of lung, ground glass opacities were used to diagnose the severity of the disease. Honeycombing like structure was not observed in any of the animal suggested that honeycombing structure may not be a characteristic of experimentally induced fibrosis in mice. After 3 intravenous infusion of $\mathrm{AD}-\mathrm{MSC}$, disease characteristics like fibrosis observed by HRCT scan in bleomycin induced animals had significantly disappeared on day 21 with only few foci of ground glass opacities. This suggested that AD-MSC treatment protected lung against bleomycin induced fibrosis and improved lung architecture (Fig. 8).

\section{Discussion}

In the present study, we have investigated the potential 

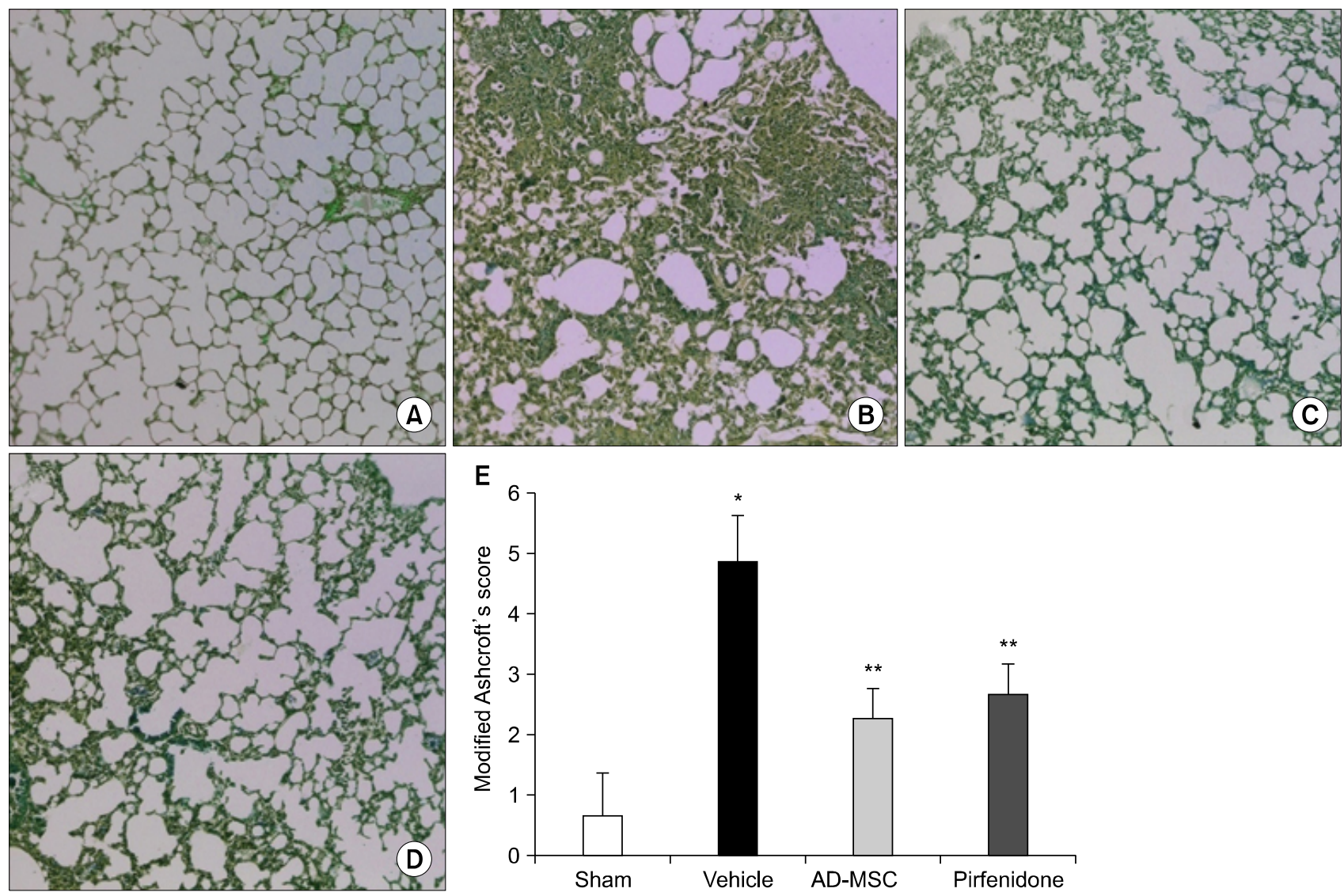

Fig. 5. Representative images of histopathology. AD-MSCs markedly inhibit bleomycin-induced histological abnormalities. (A) Representative images of Masson's trichrome stained sections of the lungs showing collagen staining in sham operated mice. (B) Represents lung of bleomycine induced mice with vehicle treatment, lung section revealed marked fibrosis and loss of architecture. (C) AD-MSC treated lung of bleomycin induced mice revealed attenuation in fibrosis with mild thickening of alveolar septa and protection against lung fibrosis and maintenance of alveolar architecture. (D) Pirfenidone treated lung with thick alveolar septa and moderately high collagen deposition. (E) Histological appearances of the Masson's trichrome stained sections were scored for fibrosis using the Ashcroft's modified scoring criteria. AD-MSC treated lung sections were compared with sham operated and vehicle treated lung. Results showed that Ashcroft's modified score in AD-MSC and Pirfenidone treated lung were significantly lowered than vehicle treated lung $(p<0.01)$. All values are averages \pm S.E.M. $190 \times 240 \mathrm{~mm}(150 \times 150 \mathrm{DPI})$.
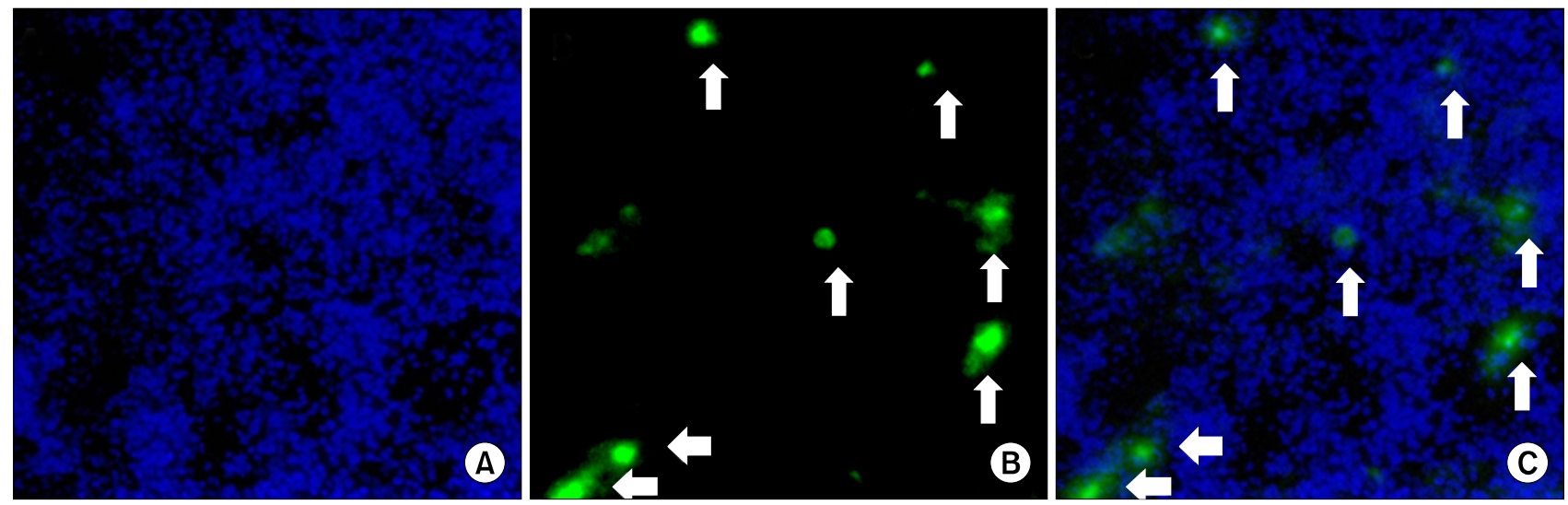

Fig. 6. Homing and engraftment potential of AD-MSCs at the site of injury. (A) Fluorescence photomicrographs of cryo-sections showing nuclear staining of mice lungs with Hoechst 33342. Nucleus is stained blue. (B) Fluorescence photomicrographs of cryo-sections showing engraftment of PKH-67 tagged AD-MSCs at the site of injury in lungs on day 24. AD-MSCs are indicated by green fluorescence. (C) Merged image showing localization of AD-MSCs in the lung parenchyma. $99 \times 244 \mathrm{~mm}(150 \times 150 \mathrm{DPI})$. 
A

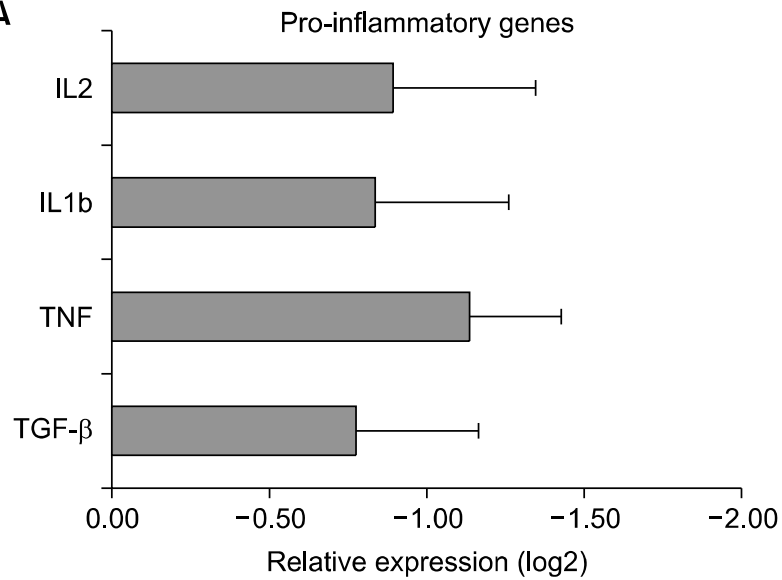

B

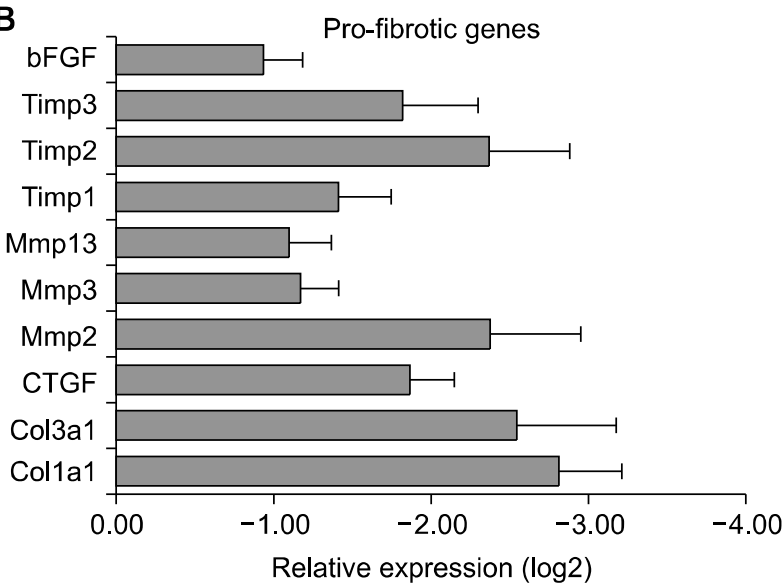

Fig. 7. Representative graph for AD-MSCs downregulate bleomycin-induced expression of pro-inflammatory and pro-fibrotic transcripts in damaged lungs. RNA isolated from tissue sections of lungs of mice from various groups was subjected to RTQ-PCR analyses using appropriate primers for: (A) Pro-inflammatory genes-TGF $\beta$, TNF, IL1b, IL2. (B) Pro-fibrotic genes-Col1a1, Col3a1, CTGF, bFGF, Mmp2, Mmp3, Mmp13, Timp1, Timp2, Timp3. Gapdh was used as the loading control. Results presented are normalized to loading control. The results are presented as the $\log 2$ fold change of mRNA expression as compared to the amount present in vehicle control samples. All values are averages \pm S.E.M. $190 \times 240 \mathrm{~mm}(150 \times 150 \mathrm{DPI})$.

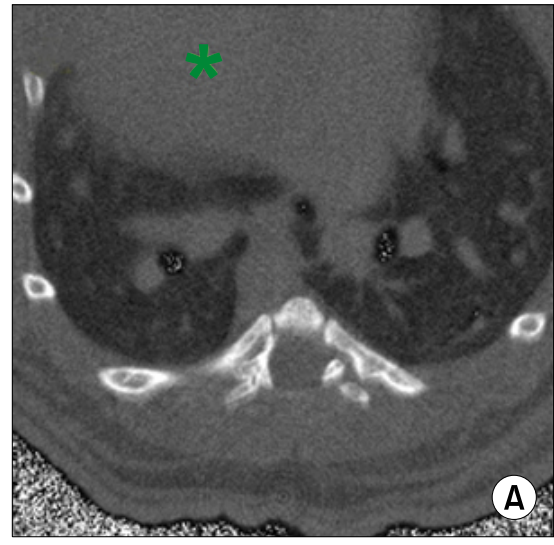

* Heart
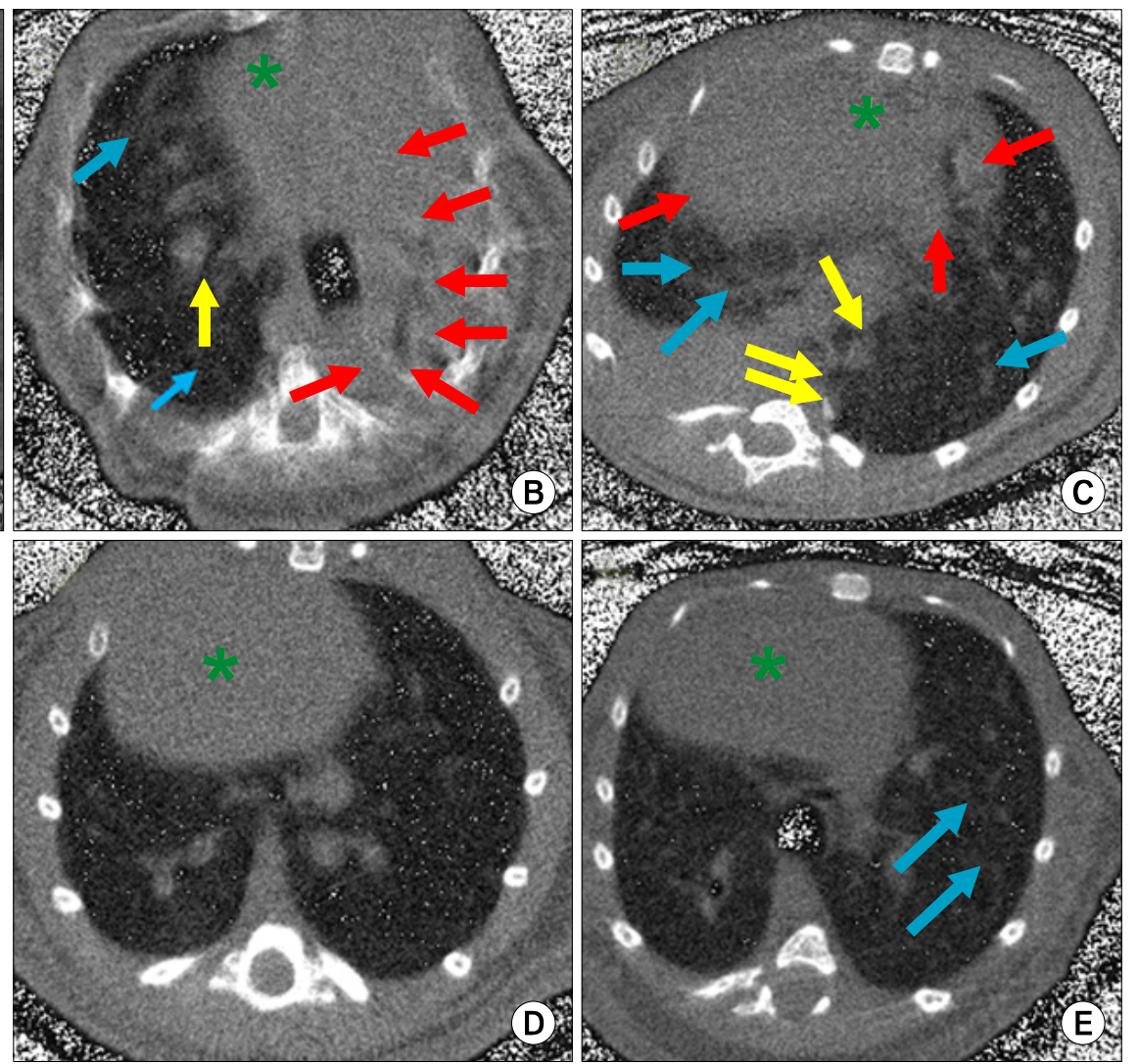

Fig. 8. Representative picture of HRCT scan (A) Naïve control animal with intact lung architecture, (B, C) Lungs of Vehicle control animals with distinct presence of severe fibrotic lesions (red arrow), consolidation of lung (yellow arrow) and ground glass opacities (blue arrow), (D) Lungs of AD-MSC treated animals showing that AD-MSC protect and reverse bleomycin induced lung fibrosis, (E) Lungs of Pirfenidone treated animals showing that pirfenidone protect and reverse bleomycin induced lung fibrosis with few ground glass opacities (blue arrow). 
of human AD-MSCs in the treatment of pulmonary fibrosis and compared with standard drug pirfenidone in bleomycin induced mice model. AD-MSC batch derived for the current study was tested for all the quality control parameters and found robust, stable and passed all the required release criteria for pre-clinical and clinical studies. In the present study, we have shown than AD-MSCs are efficacious in ameliorating the symptoms of pulmonary fibrosis by increasing survivability and protection from lung fibrosis comparatively better than pirfenidone. Earlier two studies also showed that AD-MSCs relived IPF and provide significant contribution to lung repair at an early stage of disease $(16,18)$, however, one study did not show any beneficial effect of intra-venous infusion of AD-MSCs either at 0 day or 14 day post bleomycin challenge in lung repair (27). Many studies have reported beneficial effects from MSCs derived from bone marrow, umbilical cord, and amniotic fluid for bleomycin induced lung injury in mice or rat model (28-30). Due to inconclusive results of AD-MSCs in pulmonary fibrosis in earlier studies, we attempted to check the effect of AD-MSCs in bleomycin induced pulmonary fibrosis model and compared with standard medication pirfenidone.

We used for the first time Swiss-albino strain of mice and observed that, over the first 15 days half of the vehicle control animals failed to survive single bleomycin infusion. Survivability rate was not varying when dose dependent study from 0.1 to $0.6 \mathrm{U} / \mathrm{gm}$ of bleomycin was carried out. However, dose dependent severity of lung fibrosis was seen during the study (data not shown). Earlier it was reported that Swiss-Albino strain of mice has moderate susceptibility (31) but in the present study severe pulmonary fibrosis was observed with single bleomycin infusion. Numbers of genetic factors have been linked to the development of fibrosis. Evidence suggested that inbred mouse strain with different genetic background demonstrated variable susceptibility to a fibrotic injury (32).

Although, bleomycin mouse model is not a perfect model to study pulmonary fibrosis, however, it is a most standard and most widely used model for IPF study (33). Bleomycin induced fibrotic lesions are similar with that of IPF, but fibrosis in bleomycin has several key differences from human including its reversibility, rapid onset and progression than human (34). We followed the guidelines that were established to measure most relevant parameters in bleomycin induced mice model (24).

Human AD-MSCs when administered systemically homed into the lung and were retained in the alveolar space up to the end of study from last infusion. Notably, MSC were not detected in the lung of naive animal at the end of study, implying that tissue injury is necessary to attract MSCs in the lung through chemotactic signals and exert patterned anti-inflammatory responses depending on the specific inflammatory environment and is protective against subsequent development of fibrotic changes (35) without eliciting graft versus host disease (GVHD).

We have selected 3 infusions of AD-MSC on day 3, 6 and 9 post bleomycin inductions. The kinetics of pulmonary fibrosis after bleomycin instillation follows a specific predictable pattern that can be used to determine the ideal point for commencement of treatment. Intra-tracheal administration induces immediate inflammation in the alveolar and interstitial spaces that causes oedema due to T-cell infiltration by day 7 (36). By the day 14, there is mitigation in inflammation and the fibrotic restructuring phase is underway. The fibrotic foci observed at this stage grow in size as the disease progress and by day 28, large fibrotic areas and severely collapsed alveolar spaces are evident in the tissue. Therefore, for maximum efficacy we selected days 3, 6 and 9 for AD-MSC administration in order to target both aspects of the disease, inflammatory and fibrotic. Administration of AD-MSCs at different stages during the disease phase had a multi-factorial effect of the progression of pulmonary fibrosis in Swiss albino mice. Administration on day 3, when the alveolar microenvironment was severely inflamed induced the paracrine mechanism of AD-MSCs which then initiated the mitigation of inflammation. The day 6 dose served as a booster dose to maintain this effect and further act against infiltrating T-cells. The day 9 dose was administered to target the fibrotic stages of the disease.

The available literature on MSC administration in the bleomycin model supports the concept that administration of MSCs during the acute inflammation provoked by bleomycin effectively decreases the inflammation and inhibits subsequent development of fibrosis $(18,29,30,37)$. There is no available data suggesting that MSC administration once fibrosis is established will decrease fibrosis, rather several studies suggested that MSCs administration at the fibrotic lungs may not be effective, rather may increase lung fibrosis $(27,38,39)$. Our attempt to infuse AD-MSC at fibrotic stage on day 14, 17 and 20 post bleomycin did not yield any results since most of the animals did not survive (data not shown). This may be perhaps due to severity of the disease and addressing this question is fundamental because it will not only determine the mechanism of action but also the potential toxicity of MSCs in patients with IPF (39). Similar studies were carried out using pirfenidone by day 15 post bleomycin revealed reduction in hydroxyproline content but did not reduce fibrosis. 
These results were almost indistinguishable when compared with early treatment (11). These failures may be due to failure of sufficient migration of MSCs into the fibrotic area in order to inhibit increasing interstitial fibrosis when they were administered two to three weeks after bleomycin instillation (27). The timing of cell transplantation may therefore be a key determinant of the fate and function of stem cell, since cell survival and migration depended on the time of transplantation relative to injury.

AD-MSC treatment effects were associated with normalized pulmonary expression of pro-fibrotic proteins like hydroxyproline content in the lung, overall lung weight, reduction in expression of collagen mRNA and restoration of alveolar architecture at the end of study. Several genes have been implicated in the inflammation pathways in pulmonary fibrosis progression. Upregulation of TGF- $\beta$ leads to a cascade of events since it regulates the activities of other cytokines such as TNF- $\alpha$, IL- $1 \beta$, bFGF and CTGF at various stages in the disease (33). TNF $\alpha$ and IL-1 $\beta$ induce acute inflammation, upregulation of vascular cell adhesion molecule (VCAM)-1 in endothelial cells and act as chemoattractant for infiltrating immune cells (40). This milieu coupled with increased levels of TGF- $\beta$ act as a potent inducer for AD-MSCs migration to the site of injury. The upregulated VCAM-1 in the endothelial cells further serves to strengthen the adhesive capacity of MSCs to the resident endothelial cells. Our results demonstrated that, AD-MSCs after engraftment at the site of injury cause significant reduction in pro-inflammatory markers like TGF- $\beta$, TNF- $\alpha$, IL-1 and IL-2 and pro-fibrotic markers like bFGF, CTGF, Collagen, MMP and TIMP.

However, one of the most intriguing questions is that $\mathrm{AD}-\mathrm{MSC}$ also secretes several trophic factors including pro-fibrotic and pro-inflammatory factors like TGF- $\beta$, PDGF, IGF-1 and IL-4 which are known to be associated with the regulation of fibrosis. These factors induce expression of amphiregulin (AR) in lung fibroblast that induce proliferation of fibroblast, transdifferentiate into myofibroblasts and accumulation of ECM (41). Therefore, it is a matter of investigation why these pro-fibrotic growth factors and cytokines released by AD-MSCs do not exacerbate fibrosis, but rather they inhibit the fibrosis. Notably, we have seen significant downregulation of profibrotic and pro-inflammatory transcript in alveolar tissue after AD-MSCs infusion. AD-MSCs inhibit the signalling pathway through hepatocyte growth factor (HGF) and have an ability to inhibit Wnt-3a and TGF- $\beta 1$ induced fibroblast differentiation and disrupts its pro-fibrotic action (42). Studies have demonstrated that HGF play important role in preventing fibrosis after injury (42). When we analysed the AD-MSC conditioned media (CM) by cytokine human multiplex panel using Luminex platform, we found several growth factors, cytokines, chemokines and basic proteins secreted by AD-MSCs in the media. HGF was prominently present in biologically relevant concentration i.e. $122 \mathrm{ng} / \mathrm{ml}$. These factors make AD-MSCs an ideal candidate for targeting early stage pulmonary fibrosis.

In summary, the findings from our study provide direct evidence that AD-MSCs, after systemic administration, home in to the site of injury due to paracrine mechanisms, engraft in the lung parenchyma wherein due to their immunomodulatory potential, inhibit the production of proinflammatory cytokines and pro-fibrotic mediators, and are efficacious in ameliorating the symptoms of pulmonary fibrosis. Despite the limitation of the present animal model of lung fibrosis, our findings support a beneficial effect of MSCs in lung fibrosis better than pirfenidone, but only if they are administered early stage of active inflammation but not after development of fibrosis.

\section{Acknowledgments}

This work was supported by internal funding. Authors thank Prakash Wadkar and his team for assistance in experimental animal study, Rustom Ginwala for help in procuring adipose tissue from human donors and Pradeep Chaudhary from ACTREC for assisting in HRCT. Authors also thank Nicole Koshy and Sneha Laghate for technical assistance. This research work was supported by internal funding.

\section{Potential conflict of interest}

All authors have read the journal's policy on conflict of interest Authors have no potential conflict of interest to disclose. The authors alone are responsible for content and writing of the paper.

\section{References}

1. Hutchinson J, Fogarty A, Hubbard R, McKeever T. Global incidence and mortality of idiopathic pulmonary fibrosis: a systematic review. Eur Respir J 2015;46:795-806

2. King TE Jr, Pardo A, Selman M. Idiopathic pulmonary fibrosis. Lancet 2011;378:1949-1961

3. Bagnato G, Harari S. Cellular interactions in the pathogenesis of interstitial lung diseases. Eur Respir Rev 2015; 24:102-114

4. Wolters PJ, Collard HR, Jones KD. Pathogenesis of idiopathic pulmonary fibrosis. Annu Rev Pathol 2014;9:157-179

5. Ono M, Ohkouchi S, Kanehira M, Tode N, Kobayashi M, Ebina $M$, Nukiwa $T$, Irokawa $T$, Ogawa $H$, Akaike $T$, 
Okada Y, Kurosawa H, Kikuchi T, Ichinose M. Mesenchymal stem cells correct inappropriate epithelial-mesenchyme relation in pulmonary fibrosis using stanniocalcin-1. Mol Ther 2015;23:549-560

6. Rock JR, Barkauskas CE, Cronce MJ, Xue Y, Harris JR, Liang J, Noble PW, Hogan BL. Multiple stromal populations contribute to pulmonary fibrosis without evidence for epithelial to mesenchymal transition. Proc Natl Acad Sci U S A 2011;108:E1475-E1483

7. Wynn TA. Integrating mechanisms of pulmonary fibrosis. J Exp Med 2011;208:1339-1350

8. King TE Jr, Bradford WZ, Castro-Bernardini S, Fagan EA, Glaspole I, Glassberg MK, Gorina E, Hopkins PM, Kardatzke D, Lancaster L, Lederer DJ, Nathan SD, Pereira CA, Sahn SA, Sussman R, Swigris JJ, Noble PW; ASCEND Study Group. A phase 3 trial of pirfenidone in patients with idiopathic pulmonary fibrosis. N Engl J Med 2014; 370:2083-2092

9. Richeldi L, du Bois RM, Raghu G, Azuma A, Brown KK, Costabel U, Cottin V, Flaherty KR, Hansell DM, Inoue Y, Kim DS, Kolb M, Nicholson AG, Noble PW, Selman M, Taniguchi H, Brun M, Le Maulf F, Girard M, Stowasser S, Schlenker-Herceg R, Disse B, Collard HR; INPULSIS Trial Investigators. Efficacy and safety of nintedanib in idiopathic pulmonary fibrosis. N Engl J Med 2014;370:20712082

10. Noble PW, Albera C, Bradford WZ, Costabel U, du Bois RM, Fagan EA, Fishman RS, Glaspole I, Glassberg MK, Lancaster L, Lederer DJ, Leff JA, Nathan SD, Pereira CA, Swigris JJ, Valeyre D, King TE Jr. Pirfenidone for idiopathic pulmonary fibrosis: analysis of pooled data from three multinational phase 3 trials. Eur Respir J 2016;47:243-253

11. Oku H, Shimizu T, Kawabata T, Nagira M, Hikita I, Ueyama A, Matsushima S, Torii M, Arimura A. Antifibrotic action of pirfenidone and prednisolone: different effects on pulmonary cytokines and growth factors in bleomycin-induced murine pulmonary fibrosis. Eur J Pharmacol 2008;590:400-408

12. Jiang C, Huang H, Liu J, Wang Y, Lu Z, Xu Z. Adverse events of pirfenidone for the treatment of pulmonary fibrosis: a meta-analysis of randomized controlled trials. PLoS One 2012;7:e47024

13. Wakitani S, Nawata M, Tensho K, Okabe T, Machida H, Ohgushi H. Repair of articular cartilage defects in the patello-femoral joint with autologous bone marrow mesenchymal cell transplantation: three case reports involving nine defects in five knees. J Tissue Eng Regen Med 2007;1: 74-79.

14. Totey S, Totey S, Pal R, Pal R. Adult stem cells: a clinical update. J Stem Cells 2009;4:105-121.

15. Pal R, Venkataramana NK, Bansal A, Balaraju S, Jan M, Chandra R, Dixit A, Rauthan A, Murgod U, Totey S. Ex vivo-expanded autologous bone marrow-derived mesenchymal stromal cells in human spinal cord injury/paraplegia: a pilot clinical study. Cytotherapy 2009;11:897-911

16. Jiang H, Zhang J, Zhang Z, Ren S, Zhang C. Effect of transplanted adipose-derived stem cells in mice exhibiting idiopathic pulmonary fibrosis. Mol Med Rep 2015;12:59335938

17. Chambers DC, Enever D, Ilic N, Sparks L, Whitelaw K, Ayres J, Yerkovich ST, Khalil D, Atkinson KM, Hopkins PM. A phase $1 \mathrm{~b}$ study of placenta-derived mesenchymal stromal cells in patients with idiopathic pulmonary fibrosis. Respirology 2014;19:1013-1018

18. Lee SH, Lee EJ, Lee SY, Kim JH, Shim JJ, Shin C, In KH, Kang KH, Uhm CS, Kim HK, Yang KS, Park S, Kim HS, Kim YM, Yoo TJ. The effect of adipose stem cell therapy on pulmonary fibrosis induced by repetitive intratracheal bleomycin in mice. Exp Lung Res 2014;40:117-125

19. Tzouvelekis A, Paspaliaris V, Koliakos G, Ntolios P, Bouros E, Oikonomou A, Zissimopoulos A, Boussios N, Dardzinski B, Gritzalis D, Antoniadis A, Froudarakis M, Kolios G, Bouros D. A prospective, non-randomized, no placebo-controlled, phase Ib clinical trial to study the safety of the adipose derived stromal cells-stromal vascular fraction in idiopathic pulmonary fibrosis. J Transl Med 2013;11:171

20. Srour N, Thébaud B. Mesenchymal Stromal Cells in Animal Bleomycin Pulmonary Fibrosis Models: A Systematic Review. Stem Cells Transl Med 2015;4:1500-1510

21. Gowda S, Hari A, Chougule B, Reddy MK, Chandanan A, Sodhi M, Koshy N, Fonseca L, Totey S. Production of good manufacturing practice grade equine adipose-derived mesenchymal stem cells for therapeutic use. J Stem Cell Res Ther 2013. doi:10.4172/2157-7633.1000154.

22. Nekanti U, Rao VB, Bahirvani AG, Jan M, Totey S, Ta M. Long-term expansion and pluripotent marker array analysis of Wharton's jelly-derived mesenchymal stem cells. Stem Cells Dev 2010;19:117-130

23. Govindasamy V, Ronald VS, Totey S, Din SB, Mustafa WM, Totey S, Zakaria Z, Bhonde RR. Micromanipulation of culture niche permits long-term expansion of dental pulp stem cells--an economic and commercial angle. In Vitro Cell Dev Biol Anim 2010;46:764-773

24. Matute-Bello G, Downey G, Moore BB, Groshong SD, Matthay MA, Slutsky AS, Kuebler WM; Acute Lung Injury in Animals Study Group. An official American Thoracic Society workshop report: features and measurements of experimental acute lung injury in animals. Am J Respir Cell Mol Biol 2011;44:725-738

25. Lopera D, Naranjo T, Hidalgo JM, de Oliveira Pascarelli BM, Patiño JH, Lenzi HL, Restrepo A, Cano LE. Pulmonary abnormalities in mice with paracoccidioidomycosis: a sequential study comparing high resolution computed tomography and pathologic findings. PLoS Negl Trop Dis 2010;4:e726

26. Hübner RH, Gitter W, El Mokhtari NE, Mathiak M, Both M, Bolte H, Freitag-Wolf S, Bewig B. Standardized quantification of pulmonary fibrosis in histological samples. Biotechniques 2008;44:507-511

27. Uji M, Nakada A, Nakamura T. Intravenous administration of adipose-derived stromal cells does not ameliorate bleomycin-induced lung injury in rats. Open J Regen Med 
2013;2:39-45.

28. Moodley Y, Atienza D, Manuelpillai U, Samuel CS, Tchongue J, Ilancheran S, Boyd R, Trounson A. Human umbilical cord mesenchymal stem cells reduce fibrosis of bleomycin-induced lung injury. Am J Pathol 2009;175:303-313

29. Rojas M, Xu J, Woods CR, Mora AL, Spears W, Roman J, Brigham KL. Bone marrow-derived mesenchymal stem cells in repair of the injured lung. Am J Respir Cell Mol Biol 2005;33:145-152.

30. Ortiz LA, Gambelli F, McBride C, Gaupp D, Baddoo M, Kaminski N, Phinney DG. Mesenchymal stem cell engraftment in lung is enhanced in response to bleomycin exposure and ameliorates its fibrotic effects. Proc Natl Acad Sci U S A 2003;100:8407-8411

31. Schrier DJ, Kunkel RG, Phan SH. The role of strain variation in murine bleomycin-induced pulmonary fibrosis. Am Rev Respir Dis 1983;127:63-66.

32. Walkin L, Herrick SE, Summers A, Brenchley PE, Hoff CM, Korstanje R, Margetts PJ. The role of mouse strain differences in the susceptibility to fibrosis: a systematic review. Fibrogenesis Tissue Repair 2013;6:18

33. Moeller A, Ask K, Warburton D, Gauldie J, Kolb M. The bleomycin animal model: a useful tool to investigate treatment options for idiopathic pulmonary fibrosis? Int J Biochem Cell Biol 2008;40:362-382

34. Chua F, Gauldie J, Laurent GJ. Pulmonary fibrosis: searching for model answers. Am J Respir Cell Mol Biol 2005; 33:9-13.
35. Keating A. Mesenchymal stromal cells: new directions. Cell Stem Cell 2012;10:709-716.

36. Liu R, Ahmed KM, Nantajit D, Rosenthal FS, Hai CX, Li JJ. Therapeutic effects of alpha-lipoic acid on bleomycin-induced pulmonary fibrosis in rats. Int $\mathrm{J}$ Mol Med 2007;19:865-873.

37. Zhou MI, Chen DL, Jiang T, Feng YM, Han XL. Effects of bone marrow-derived mesenchymal stem cells transfected with survivin on pulmonary fibrosis in mice. Exp Ther Med 2015;10:1857-1864

38. McNulty K, Janes SM. Stem cells and pulmonary fibrosis: cause or cure? Proc Am Thorac Soc 2012;9:164-171

39. Weiss DJ, Ortiz LA. Cell therapy trials for lung diseases: progress and cautions. Am J Respir Crit Care Med 2013; 188:123-125

40. Yagi H, Soto-Gutierrez A, Parekkadan B, Kitagawa Y, Tompkins RG, Kobayashi N, Yarmush ML. Mesenchymal stem cells: Mechanisms of immunomodulation and homing. Cell Transplant 2010;19:667-679

41. Samad S, Akram KM, Forsyth NR, Spiteri M. Mesenchymal Stem Cell Conditioned Media (MSC-CM) suppress Wnt-3a and TGF- $\beta 1$ - induced myofibroblastic differentiation. J Stem cell Res, Rew \& Rep 2014;1:1015

42. Gazdhar A, Grad I, Tamò L, Gugger M, Feki A, Geiser T. The secretome of induced pluripotent stem cells reduces lung fibrosis in part by hepatocyte growth factor. Stem Cell Res Ther 2014;5:123 